Correction

\title{
Correction to: Effects of copper oxide nanoparticles on the Chlorella algae in the presence of humic acid
}

\author{
Parvin Fathi ${ }^{1}$ - Gholamreza Sadeghi ${ }^{1}$ - Mir-Jamal Hosseini ${ }^{2} \cdot$ Zohreh Farahmandkia $^{1} \cdot$ Mohammad Reza Mehrasbi $^{1}$
}

Published online: 17 February 2020

(c) Springer Nature Switzerland AG 2020

\section{Correction to: SN Applied Sciences (2020) 2:140 https://doi.org/10.1007/s42452-019-1812-6}

There were errors in the second and fifth authors' names in the original article. The correct name are listed here. The original article has been corrected.

Publisher's Note Springer Nature remains neutral with regard to jurisdictional claims in published maps and institutional affiliations.

The original article can be found online at https://doi.org/10.1007/s42452-019-1812-6.

$\square$ Mohammad Reza Mehrasbi, zmehr@zums.ac.ir; mehrasbi@yahoo.com; Parvin Fathi, fathi.parvin@yahoo.com; Gholamreza Sadeghi, sadeghi@zums.ac.ir; Mir-Jamal Hosseini, hosseinij@zums.ac.ir; Zohreh Farahmandkia, zfarahmand@zums.ac.ir|Department of Environmental Health, School of Public Health, Zanjan University of Medical Sciences, Zanjan, Iran. ${ }^{2}$ Department of Toxicology, School of Pharmacy, Zanjan University of Medical Sciences, Zanjan, Iran. 